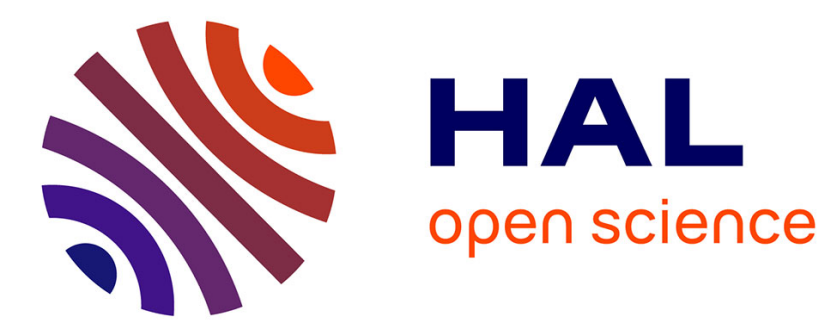

\title{
Kinetic analysis and modelling of PET macromolecular changes during its mechanical recycling by extrusion
}

\author{
Linda K. Nait-Ali, Xavier Colin, Anne Bergeret
}

\section{To cite this version:}

Linda K. Naït-Ali, Xavier Colin, Anne Bergeret. Kinetic analysis and modelling of PET macromolecular changes during its mechanical recycling by extrusion. Polymer Degradation and Stability, 2011, 96 (2), pp.236-246. 10.1016/j.polymdegradstab.2010.11.004 . hal-02455994

\author{
HAL Id: hal-02455994 \\ https://hal.science/hal-02455994
}

Submitted on 27 Jan 2020

HAL is a multi-disciplinary open access archive for the deposit and dissemination of scientific research documents, whether they are published or not. The documents may come from teaching and research institutions in France or abroad, or from public or private research centers.
L'archive ouverte pluridisciplinaire HAL, est destinée au dépôt et à la diffusion de documents scientifiques de niveau recherche, publiés ou non, émanant des établissements d'enseignement et de recherche français ou étrangers, des laboratoires publics ou privés. 


\title{
Kinetic analysis and modelling of PET macromolecular changes during its mechanical recycling by extrusion
}

\author{
Linda K. Nait-Ali ${ }^{\mathrm{a}, 1}$, Xavier Colin ${ }^{\mathrm{b}, *}$, Anne Bergeret ${ }^{\mathrm{c}, 2}$ \\ a Terre Armee Internationale, REDD Division, 1 bis rue du Petit Clamart, Bâtiment C, B.P. 135, 78148 Vélizy-Villacoublay, France \\ ${ }^{\mathrm{b}}$ Arts et Metiers ParisTech, PIMM (UMR CNRS 8006), 151 boulevard de l'Hôpital, 75013 Paris, France \\ 'Ecole des Mines d'Alès, CMGD, 6 Avenue de Clavières, 30100 Alès, France
}

Keywords:

Poly(ethylene terephthalate)

Mechanical recycling by extrusion

Thermal oxidation

Chain scission and coupling

Kinetic modelling

\begin{abstract}
A B S T R A C T
The rheometer cavity has been chosen to analyze, in carefully controlled exposure conditions, the PET macromolecular changes generated during its mechanical recycling by extrusion. Isothermal ageing experiments at $280{ }^{\circ} \mathrm{C}$, under constant or variable oxygen partial pressures (between $0 \%$ and $21 \%$ of the atmospheric pressure), have allowed us to establish that two types of oxidative macromolecular changes take place successively in an extruder reactor. Chain scissions predominate in the "strongly oxygenated" zones (at the feeder and die), whereas chain couplings (mainly chain branching) predominate in "poorly oxygenated" zones (in the middle of the reactor). Thus, it appears that the relative predominance of both types of modifications is closely related to the extruder geometry and size (in particular, the feeder and die sections and the screw length). A kinetic model of thermal ageing of molten PET has been built to check these assumptions. It describes satisfyingly all the rheometric results obtained in the present study.
\end{abstract}

\section{Introduction}

The recycling of poly(ethylene terephthalate) (PET) waste is the result of societal pressure to reduce environmental pollution, but also the willingness of industrialists to develop less expensive raw materials. Currently, wastes come essentially from the food packaging industry: bottles of mineral water or soda, packaging trays and films, etc. They are re-used after recycling (that is to say separation, grinding, washing and drying) for the production of textile fibres or new bottles.

An important part of the literature is dedicated to the study of PET mechanical recycling, that is to say the melt reprocessing of flakes resulting from recycling (generally by extrusion, but also by injection moulding); this recycling can be made by mixing 10 to $20 \mathrm{wt} \%$ of virgin polymer. The main reason of this interest seems to be the diversity and complexity of (ionic and radical) chemical reactions involved during this processing, for instance:

\footnotetext{
* Corresponding author. Tel.: +33144246147.

E-mail addresses: linda.nait-ali@terre-armee.com (L.K. Nait-Ali), xavier.colin@ paris.ensam.fr (X. Colin), anne.bergeret@ema.fr (A. Bergeret).

1 Tel.: +33146018571.

2 Tel.: +3346678 5344
}

- Ester groups' hydrolysis [1-6];

- Esterification of carboxyl and hydroxyl ethyl ester chain ends [1-6];

- Transesterification of hydroxyl ethyl ester chain ends pairs [4], and hydroxyl ethyl ester and vinyl ester chain ends [3,5-9];

- Thermal decomposition of ester groups from ethylene glycol unit (i.e. monomer unit) [3,5-22], from diethylene glycol units, considered as the main structural irregularities in PET (between 1 and $3.6 \mathrm{~mol} \%$ [23]) [8,23-26], and of hydroxyl ethyl ester $[4,6,8,10,13,14,20,24]$ and vinyl ester $[6,10,14,16,18,20,26]$ chain ends;

- Thermal oxidation of methylene groups from ethylene glycol [3-6,9,11,21] and diethylene glycol units [3,23,25,27];

- Decarbonylation of acyl radicals and decarboxylation of carboxyl radicals $[15,16,18,27]$;

- Thermal oxidation of aromatic cycles [15];

- Hydroxylation of aromatic cycles [15,16,19,23,24,26,28];

- Condensation of carboxylic acid chain ends pairs $[5,6,10,22,24,26]$ and carboxylic acid and vinyl ester chain ends $[3,5,6,8,9,14,16,24]$;

- Polyaddition of vinyl ester chain ends [3,6,8,9,18,23];

- Polyaddition of aromatic cycles [20].

Hydrolysis/esterification reactions lead to structural changes that can be considered as reversible, if the water concentration into 
the polymer is well controlled. Indeed, we know that if the moisture content exceeds a value of $0.01-0.02 \mathrm{wt} \%[3,29]$, the hydrolysis of ester groups leads to the formation of carboxyl acid and hydroxyl ethyl ester chain ends, which results in a catastrophic drop of the molecular mass with the residence time in a processing machine. The polymer can be then easily regenerated by heating in a dry state. But, generally hydrolysis is totally avoided by a careful drying of granules/flakes before processing.

It is the same for transesterification reactions. However, all other chemical reactions lead to irreversible structural changes, responsible for a more or less marked narrowing of the processing window [30]. In the case of extrusion, the residence time of molten polymer is quite long (typically between 1 and $2 \mathrm{~min}$ ) and it is now well established that the polymer thermal oxidation is the main source of problems [24,31-38]. In the case of injection moulding, although the residence time of the molten polymer is significantly shorter (few seconds), it seems that the thermal oxidation plays also an important role [39-41]. In the temperature range of molten PET processing (typically between 210 and $280{ }^{\circ} \mathrm{C}$ ), it is now recognized that thermal oxidation is a radical chain mechanism, essentially initiated by the decomposition of its main propagation product: the hydroperoxide group $\mathrm{POOH}[3,4,6,9,21,24,26,27$, 35,36].

In general, molten PET thermal ageing leads to two main types of structural changes:

- Modification of lateral groups, principally the formation of hydroxyl and carbonyl groups [5,6,9,11,12,15,16,21,23,24, 26-28], but also several types of conjugated structures $[3,5,6,8,9,15,16,20,23,26]$;

- Modification of macromolecular structure, that is to say chain scissions [3-27,31-43] and chain extensions and branching $[3,5,6,8-10,14,16,20,22-24,26,35,36]$, and eventually crosslinking [35].

The macromolecular changes affect as well the polymer rheological behaviour in solution or in molten state (changes in viscosity) $[3,5-7,9,18,24,31-38,40-42]$ as the polymer mechanical behaviour in solid-state (catastrophic drop of fracture properties) $[27,31,33,34,38-41,44]$, even at very low conversion ratios. It is now well established that chain scissions lead to the formation of new chain extremities of aldehyde [5,6,9,16,18,21,43], formate [23,27], carboxylic acid [3-12,14,16,18-24,26,27,33,34,39-42] and vinyl ester types [3-10,12,14-16,18,20-24,26]. If they occur near a chain end, they also lead to the formation of several types of low molar mass organic volatile compounds (OVC). They are, for example, carbon monoxide $[3,5,6,10,16,18,27]$, carbon dioxide $[3,5,6,10,11$, $15,16,18,20,21,23,25-27]$, methane $[3,5,6,10]$, ethylene $[3,5,6,10]$, benzene $[3,5,6,27]$, but also aldehydes such as benzaldehyde $[10,18]$, formaldehyde $[13,15,17,21,27,43]$ and acetaldehyde [3-18,20,22,24-26,43]. Acetaldehyde would be, by far, the main
OVC, since it would represent about $80 \mathrm{~mol} \%$ of the total amount of OVC $[3,5,6]$. The formation of aldehydes is a real problem in the food packaging industry, because these molecules can be temporarily trapped in the glassy amorphous phase of the semi-crystalline polymer at room temperature and then, affects the organoleptic properties of food or drinks without flavour such as mineral water.

On the contrary, chain couplings (i.e. chain extensions and branching) lead to the formation of new groups in the carbon chain skeleton. Unfortunately, the low sensitivity of common laboratory analytical techniques (IR spectrophotometry, solid ${ }^{13} \mathrm{C}$ RMN, etc.) does not allow the characterization of these structures with a sufficient reliability. They would be essentially anhydrides $[3,5,6,8-10,14,22,24,26,36]$, methyne groups $[3,6,8,9,23,35,36,45]$, or bi- and tri-phenyl structures $[20,26]$.

However, the changes in lateral groups do not affect the polymer rheological or mechanical behaviour at low conversion ratio, but more specific use properties such as optical or electrical properties. The most important problem, in practice, is the polymer discoloration which results from the presence of chromophoric groups, even in very low concentrations. The main chromophoric groups would be anhydrides [3,5,6,8-12,14,16,22,24,26,27,36], phenols $[15,16,23,24,26,28]$ which would be transformed into aromatic ketones of quinone type $[15,16,23,28]$, conjugated ketoesters [26], various conjugated aromatic structures $[15,16,20,26]$, but also polydiene sequences $[3,5,6,8,9,23]$.

The present article is dedicated to the study of irreversible PET macromolecular changes during its mechanical recycling by extrusion. The study will be conducted in two successive stages: At first, the proposal of a sufficiently sensitive method to highlight the consequences of these changes on the polymer rheological behaviour; Then, the development of a kinetic model for PET thermal ageing at high temperatures - in molten state - in order to identify, within the set of possible reaction mechanisms proposed in the literature, those which are effectively responsible for these changes.

\section{Theory}

\subsection{First observations}

So, there is a large consensus, in the literature, on the fact that thermal oxidation is the main source of problems during PET mechanical recycling by extrusion [24,31-38]. However, opinions differ on the evolution of PET macromolecular structure (see Table 1).

Values of weight average molar mass Mw have been plotted versus the number of extrusion operations in Fig. 1. These values have been determined by viscometry, either in solution at ambient temperature [24,33,34], or in molten state at 270 or $280{ }^{\circ} \mathrm{C}$ $[31,35,36]$, using the classical Mark-Houwink's equation:

Table 1

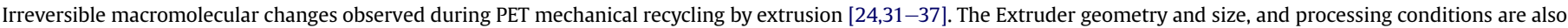
reported.

\begin{tabular}{|c|c|c|c|c|c|c|}
\hline References & De Paoli [24,34] & La Mantia [31,32] & Frounchi [33] & Assadi [35] & Nait-Ali [36] & Ribes-Greus [37] \\
\hline Extruder & $\begin{array}{l}\text { Wortex WEX } 30 \\
\text { single screw }\end{array}$ & $\begin{array}{l}\text { Brabender PLE } 640 \\
\text { single screw }\end{array}$ & $\begin{array}{l}\text { Collin Nr } 5500 \\
\text { twin screw }\end{array}$ & $\begin{array}{l}\text { Samafor BG } 45 \\
\text { single screw }\end{array}$ & $\begin{array}{l}\text { Fairex compact } \\
\text { single screw }\end{array}$ & $\begin{array}{l}\text { Brabender PL } 2000 \\
\text { twin screw }\end{array}$ \\
\hline Feeder section $\left(\mathrm{mm}^{2}\right)$ & - & - & - & 1800 & 3800 & - \\
\hline Screw length $(\mathrm{cm})$ & 96 & 47.5 & - & 110 & 88 & 75 \\
\hline Die section $\left(\mathrm{mm}^{2}\right)$ & - & - & - & 63 & 80 & - \\
\hline Temperature profile $\left({ }^{\circ} \mathrm{C}\right)$ & $220-280$ & $210-270$ & $235-260$ & $240-280$ & $220-260$ & $250-270$ \\
\hline Rate (rpm) & 102 & 100 & 62 & 40 & 80 & - \\
\hline Residence time (s) & 120 & - & - & 90 & 50 & - \\
\hline $\begin{array}{l}\text { Main degradation } \\
\text { mechanisms }\end{array}$ & Chain scissions & Chain scissions & Chain scissions & $\begin{array}{l}\text { Chain scissions } \\
\text { and couplings }\end{array}$ & $\begin{array}{l}\text { Chain scissions } \\
\text { and couplings }\end{array}$ & Chain scissions \\
\hline
\end{tabular}




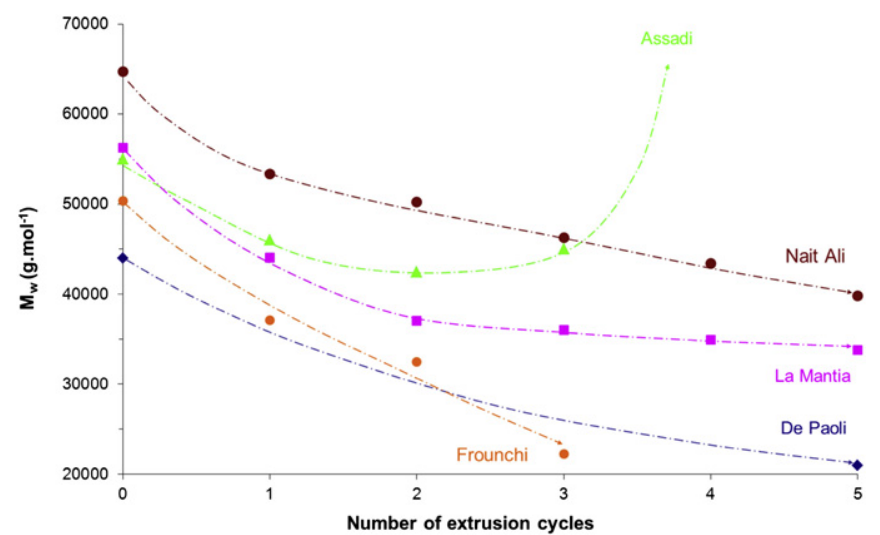

Fig. 1. Changes in weight average molar mass versus number of extrusion cycles according to different authors [24,31,33-36].

$\eta \approx \mathrm{K} \mathrm{M}_{\mathrm{W}}^{\alpha}$

where $\mathrm{K}$ is a decreasing function of temperature and $\alpha \approx 0.7$ in solution (in this case, $\eta$ is noted VI and called "intrinsic viscosity") and $\approx 3.4$ in molten state (in this case, $\eta$ is called "Newtonian viscosity").

In the majority of cases [24,31-34,36-38], mechanical recycling leads to a large predominance of chain scissions, which results in a monotonous decrease of $\mathrm{M}_{\mathrm{W}}$ and viscosity $\eta$. However, in two cases [35,36], it also leads to chain couplings which, finally, can predominate over chain scissions. After a certain time of exposure, depending on the aggressiveness of thermal exposure conditions, it results in a re-increase of $\mathrm{M}_{\mathrm{w}}$ and $\eta$. In one of these latter (Assadi et al. [35]), polymer gelation (by crosslinking) is even observed during the fourth extrusion cycle, causing a complete obstruction of the extruder.

An original way to detect the formation of branched structures, below the gel point, was proposed by Assadi et al. [35]. It consists in comparing the $\mathrm{M}_{\mathrm{W}}$ values determined by two different analytical techniques: viscometry (in molten state) and Steric Exclusion Chromatography (SEC) (see Fig. 2). If the polymer remained linear (case of initial polymer), that is to say if there were only chain scissions and chain extensions, $\mathrm{M}_{\mathrm{W}}$ values would be the same. However, since chain branching occurs simultaneously, the values are different from the first extrusion operation. This result is not

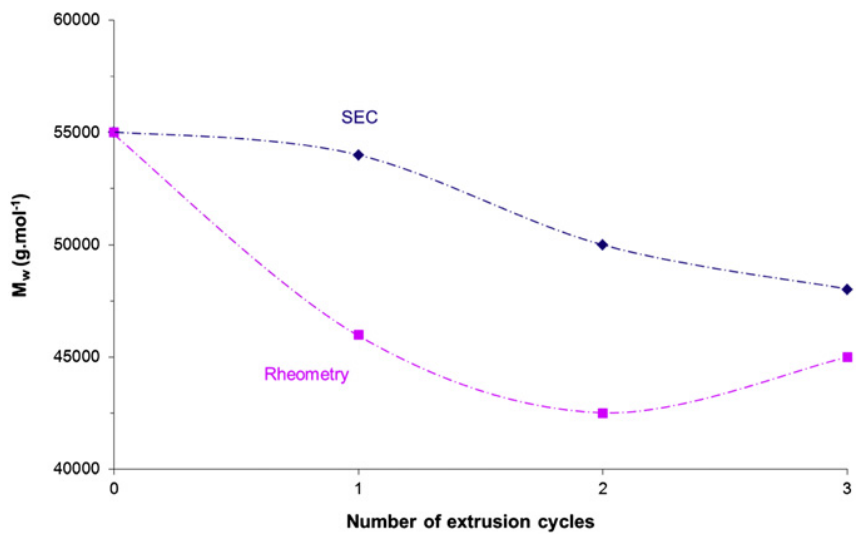

Fig. 2. Changes in weight average molar mass versus number of extrusion cycles according to Assadi et al. [35]. Comparison between average molar masses determined by viscometry (in molten state) and by Steric Exclusion Chromatography (SEC). surprising because, for the same $\mathrm{M}_{\mathrm{W}}$ value, the presence of branching prevents chain reptation in molten state, but also decreases the hydrodynamic volume of the chain in solution. Finally, there are two completely different evolution of $\mathrm{M}_{\mathrm{W}}$ with the number of extrusion cycles: the viscometric curve shows a minimum at the second extrusion cycle, attributed to a balance between chain scissions and chain branching, while chromatographic curve displays clearly a sigmoidal shape.

A more traditional way to detect branching consists in comparing the IV values, of recycled PET, and IV values of a series of linear PET, taken as reference materials (see Fig. 3) [35]. Indeed, these two polymer families follow the previous Mark-Houwink's law, but for quite different values of exponent $\alpha(\approx 0.97$ for recycled and $\approx 0.77$ for linear PET). Moreover, one can notice that the dots for recycled PET are clearly below the characteristic straight-line of linear PET, and their distance from the straight-line increases with the number of extrusion cycles. Thus, for the extrusion processing conditions studied by Assadi et al. [35], it appears that the number of ramifications increases continuously with the number of extrusion cycles. However, this change in the rheological behaviour seems to be, in a first approximation, very different from those reported by other authors [24,31-34,36-38]. How to explain such a discrepancy?

If one observes attentively Table 1 , despite a lack of information on extrusion conditions in some cases, it appears that chain scissions are widely favoured in the case of "well-oxygenated" extruders (large feeder and die sections, and short screw), and that chain couplings are only detected in the case of "poorly oxygenated" extruders (narrow feeder and die sections, and long screw). One can thus conclude that oxygen concentration would be a key parameter for PET thermal degradation in molten state.

Another important parameter, which could affect significantly the competition between chain scissions and chain couplings, is temperature. Indeed, chain couplings present, in general, a lower activation energy than chain scissions. It is thus expected that chain couplings are favoured at lower temperatures [46]. Unfortunately, the effect of temperature does not appear in Table 1, presumably because extrusions have been carried out in relatively close temperature intervals, all centred around a mean value of about $240-260^{\circ} \mathrm{C}$

At this stage, one can conclude that a complete understanding of PET mechanical recycling would require to study the variation of, at least, two parameters: oxygen concentration and temperature. The present article focuses on the effects of oxygen concentration.

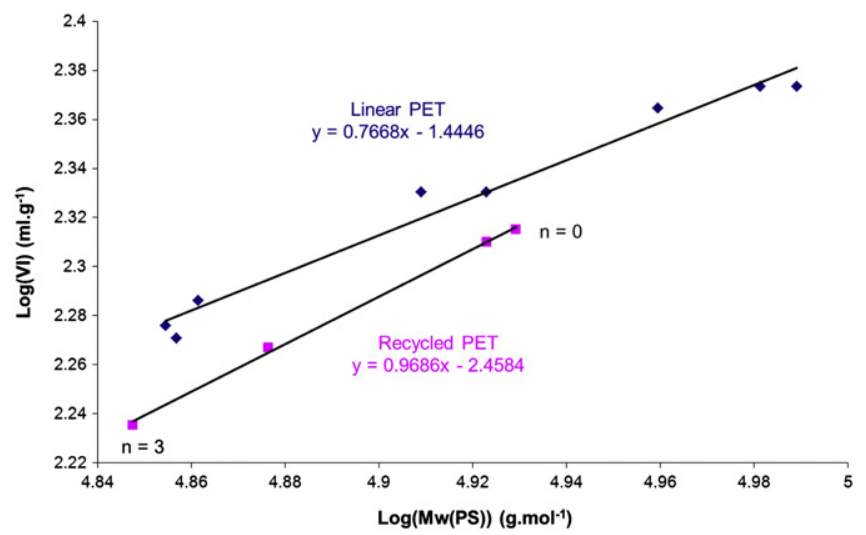

Fig. 3. Changes in intrinsic viscosity versus weight average molar mass determined by SEC. Comparison between recycled and linear (taken as a reference) PET viscosities [35]. 


\subsection{Proposal of a simplified scheme for an extruder reactor}

Although in real extrusion conditions the problem is more complicated - especially because of the mechanical transport of oxidized polymer particles along the screw - we have chosen, in a first approach, to represent an extruder reactor by a relatively simple form. We have started from the observation that the molten polymer is confined within the pressurized zone (i.e. in the middle) and is only in contact with air, at atmospheric pressure, at both extremities (at the feeder and die) of the extruder. So, at both extremities, the oxygen concentration is the highest one. It is expected that this latter decreases rapidly towards the centre of the reactor since an oxidation reaction proceeds and its kinetics is diffusion controlled [47]. However, since the temperature is not homogeneous in the reactor, the thermal oxidation will occur in a non-isothermal state.

Oxygen concentration and temperature gradients have been schematized in Fig. 4. Coordinates $\mathrm{z}_{0}$ and $\mathrm{z}_{\mathrm{L}}$ indicate the position of the air/molten polymer interfaces at the feeder and die respectively. Thus, the screw length is:

$\mathrm{L}=\mathrm{z}_{L}-\mathrm{z}_{0}$

Coordinates $z_{1}$ and $z_{2}$ are the limits between the "welloxygenated" zones ( 1 and 3 ), in which chain scissions should largely predominate, and "poorly oxygenated" zones (2), where chain couplings should be favoured. Thus, the lengths of these different zones are:

$\mathrm{L}_{1}=\mathrm{z}_{1}-\mathrm{z}_{0}$

$\mathrm{L}_{2}=\mathrm{z}_{2}-\mathrm{z}_{1}$

$\mathrm{L}_{3}=\mathrm{z}_{L}-\mathrm{z}_{2}$

The equilibrium oxygen concentration at the air/molten polymer interfaces follows the classical Henry's law:

$\left[\mathrm{O}_{2}\right]\left(\mathrm{z}_{i}\right)=\mathrm{S}_{\text {molten }}\left(\mathrm{T}_{\mathrm{i}}\right) \times \mathrm{P}_{\mathrm{O}_{2}}$

Oxygen partial pressure $\mathrm{P}_{\mathrm{O}_{2}}$ in ambient air is about $21 \%$ of atmospheric pressure, i.e. $2.1 \times 10^{4} \mathrm{~Pa}$. Moreover, in a first approach, one can estimate the oxygen solubility into the molten

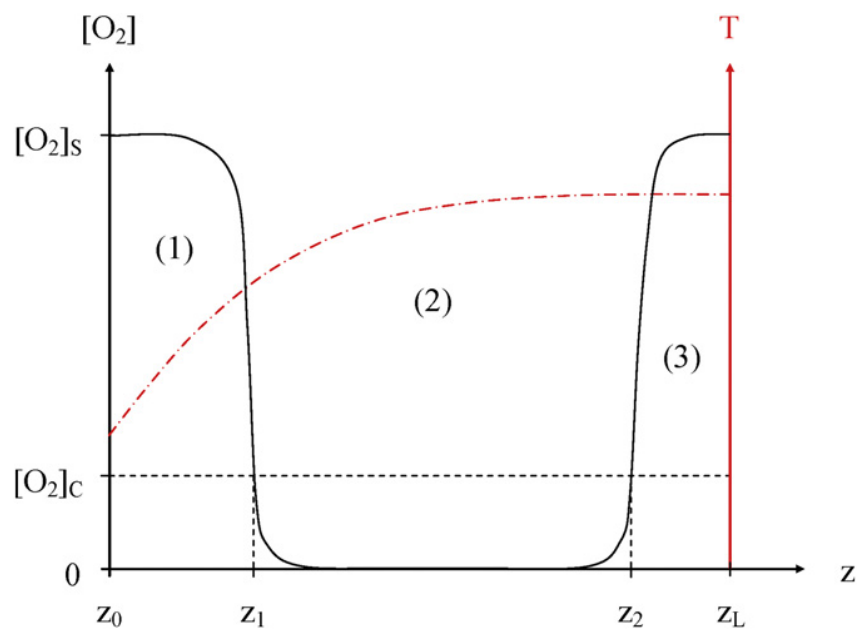

Fig. 4. Simplified scheme of an extruder reactor. $\left[\mathrm{O}_{2}\right]$ and $\mathrm{T}$ designate respectively the oxygen concentration and temperature gradients in the reactor. Positions $z_{i}$ are the limits between the different "reaction" zones (1,2 and 3$)$ in the reactor. polymer from the solubility into the semi-crystalline polymer above its glass transition temperature, knowing its crystallinity ratio:

$S_{\text {molten }}=\frac{S_{\text {semi-crist }}}{1-\chi_{c}}$

Databases [e.g. 48,49] show that oxygen solubility into polymers is almost temperature independent. The numerical application of Equs. (4) and (5), taking $\mathrm{S}_{\text {semi-crist }}=3.1 \times 10^{-8} \mathrm{~mol} \mathrm{l}^{-1} \mathrm{~Pa}^{-1}$ and $\chi_{C}=33 \%$ [49], leads finally to:

$S_{\text {molten }}=4.6 \times 10^{-8} \mathrm{~mol} \mathrm{l}^{-1} \mathrm{~Pa}^{-1}$

i.e. $\left[\mathrm{O}_{2}\right]\left(\mathrm{z}_{0}\right)=\left[\mathrm{O}_{2}\right]\left(\mathrm{z}_{1}\right)=\left[\mathrm{O}_{2}\right]_{\mathrm{S}}=9.7 \times 10^{-4} \mathrm{~mol} \mathrm{l}^{-1}$

Finally, the only unknown parameter is the oxygen critical concentration at the "oxygenated" zones/"anaerobic" zones interfaces:

$\left[\mathrm{O}_{2}\right]\left(\mathrm{z}_{1}\right)=\left[\mathrm{O}_{2}\right]\left(\mathrm{z}_{2}\right)=\left[\mathrm{O}_{2}\right]_{\mathrm{C}}$

This last one will be determined, in this study, from specific thermal oxidation experiments made under various oxygen partial pressures.

According to this simplified scheme, chain scissions and couplings will occur successively during an extrusion operation, since each one is largely favoured in a distinct zone of the reactor: in the "well-oxygenated" and "poorly oxygenated" zones respectively. Thus, finally, the relative predominance of both types of macromolecular changes depends on 4 factors:

- The screw length L;

- The length of both "well-oxygenated" zones $\mathrm{L}_{1}$ et $\mathrm{L}_{3}$;

- And the residence time $t_{R}$.

Lengths $\mathrm{L}_{1}$ and $\mathrm{L}_{3}$ depend, in turn, on 5 parameters:

- The equilibrium oxygen concentration $\left[\mathrm{O}_{2}\right]_{\mathrm{S}}$ and the rate of oxygen consumption $\mathrm{v}\left(\left[\mathrm{O}_{2}\right]_{\mathrm{S}}\right)$ at the air/molten polymer interfaces;

- The oxygen diffusivity $\mathrm{D}_{\mathrm{O}_{2}}$ into the melt;

- The temperature profile in the reactor;

- And the polymer transport rate along the screw.

We have seen that $\left[\mathrm{O}_{2}\right]_{\mathrm{S}}$ is temperature independent (see Equ. (4)). However, the ratio $\mathrm{D}_{\mathrm{O}_{2}} / \mathrm{v}\left(\left[\mathrm{O}_{2}\right] \mathrm{S}\right)$ is a decreasing function of temperature [47]. It is thus expected that: $\mathrm{L}_{1}>\mathrm{L}_{3}$.

At this stage, it is possible to define two extreme types of extruder machines:

- "Well-oxygenated" extruders, for which $\mathrm{L}_{1}>\mathrm{L}_{3}>>\mathrm{L}_{2}$, leading to chain scissions;

- And "poorly oxygenated" extruders, for which $\mathrm{L}_{2}>>\mathrm{L}_{1}>\mathrm{L}_{3}$, leading to chain couplings.

The objective of the present study is to determine if such a simplified scheme is sufficient to explain the disparity in rheological behaviours reported in literature during PET mechanical recycling.

\subsection{Use of the rheometer cavity as a tool for simulating the macromolecular changes}

An original solution to validate this simplified scheme consists in studying the PET macromolecular changes induced by 
the thermal oxidation in carefully controlled (in temperature, oxygenation and shearing) conditions. The rheometer cavity is ideal for such a study, for the following reasons:

- The temperature field is homogeneous and perfectly regulated;

- The atmosphere can be perfectly controlled and rapidly changed;

- The shear amplitudes are sufficiently low to ensure the absence of mechano-chemical degradation;

- This equipment gives a direct information on the weight average molar mass $\mathrm{M}_{\mathrm{W}}$ with a high sensitivity.

So this machine can be used to perform two thermal ageing experiments:

- Experiments to reproduce the local macromolecular changes (predominantly chain scissions or chain couplings) at a given oxygen concentration, that is to say at a given $\mathrm{z}$ position in the extruder reactor. These are isothermal experiments at a constant oxygen partial pressure, between $0 \%$ (nitrogen) and 21\% (ambient air) of atmospheric pressure;

- Experiments to reproduce the historic background of macromolecular changes (succession of chain scissions and couplings) during a complete extrusion operation. These are isothermal experiments at a variable oxygen partial pressure, between $0 \%$ and $21 \%$ of atmospheric pressure, during which the polymer is exposed under nitrogen, but with short admissions in ambient air (during approximately $2 \mathrm{~min}$ ).

\subsection{Proposal of a kinetic model for PET thermal oxidation}

The starting point is the "closed-loop" oxidation scheme established for describing the polyethylene (PE) thermal ageing, from low to moderate temperatures (typically between 40 and $220^{\circ} \mathrm{C}$ ), in a previous study [50]. Indeed, it is expected that PET behaves essentially as a poly(methylenic) substrate against oxidation and, for this reason, that its thermal oxidation mechanistic scheme is very close to PE one. However, in the temperature range under study $\left(\mathrm{T} \geq 250{ }^{\circ} \mathrm{C}\right.$ ), this scheme must be slightly improved:

- The hydroperoxide critical concentration $[\mathrm{POOH}]_{\mathrm{C}}$, beyond which thermal decomposition of $\mathrm{POOH}$ groups switches from unimolecular to bimolecular mode, is an increasing function of temperature. It is about $9.2 \times 10^{-1} \mathrm{~mol} \mathrm{l}^{-1}$ at $250^{\circ} \mathrm{C}$, that is to say that it is necessary to accumulate a considerable quantity of $\mathrm{POOH}$ groups to initiate the bimolecular mode. Thus, above $250{ }^{\circ} \mathrm{C}$, one can reasonably consider that $\mathrm{POOH}$ decomposition is essentially unimolecular;

- Molecular oxygen being a bi-radical in ground state, we cannot exclude its direct reaction with the polymer:
- Above $250{ }^{\circ} \mathrm{C}$, peroxide groups POOP cannot survive. Disproportionation is the only possible termination for alkoxy radicals pairs. It leads to the formation of anhydride and alcohol groups:

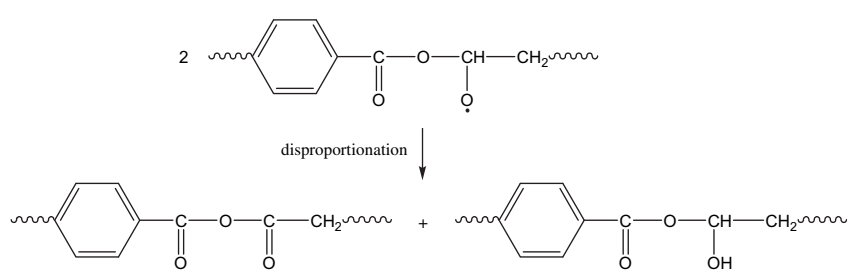

- In principle, aldehydes are the main by-products resulting from chain scissions. They are formed by $\beta$ scissions of alkoxy radicals. However, their $\mathrm{C}-\mathrm{H}$ bond presents a dissociation energy $\left(E_{D} \approx 368 \mathrm{~kJ} \mathrm{~mol}^{-1}\right)$ significantly lower than that of methylene groups $\left(E_{D} \approx 393 \mathrm{~kJ} \mathrm{~mol}^{-1}\right)$. It is thus expected that aldehydes are quickly oxidized into carboxylic acids:
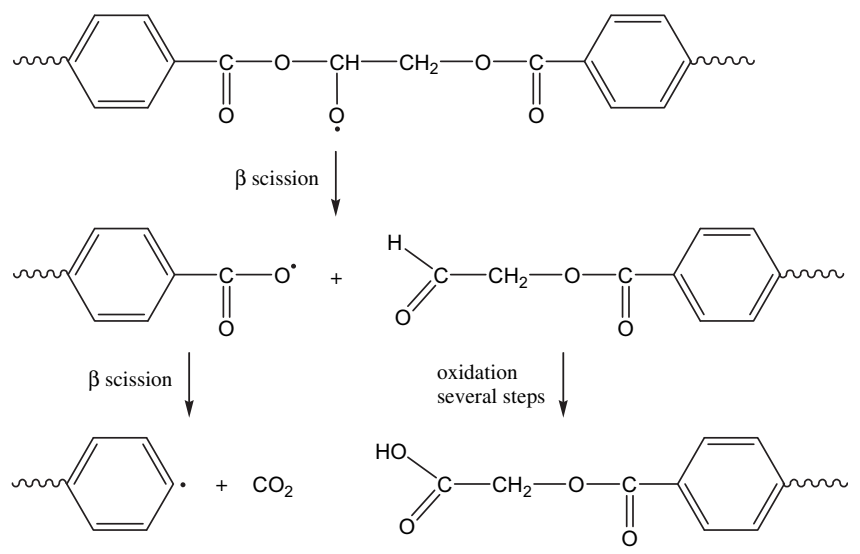

This assumption is fully justified because, in general, when they are detected, aldehydes represent a very small fraction of the whole oxidation by-products formed during the PET mechanical recycling by extrusion. In a first approach, one can replace all the aldehyde groups by carboxylic acid groups in the oxidation mechanistic scheme.

Finally, a mechanistic scheme for PET thermal oxidation in molten state could be:

$\begin{array}{lll}\mathrm{PH}+\mathrm{O}_{2} & \rightarrow \mathrm{P}^{\bullet}+\mathrm{HO}_{2} \\ \mathrm{HO}_{2}{ }^{\circ}+\mathrm{PH} & \rightarrow \mathrm{P}^{\bullet}+\mathrm{H}_{2} \mathrm{O}_{2} \\ \mathrm{H}_{2} \mathrm{O}_{2} & \rightarrow 2 \mathrm{HO}^{\bullet} \\ 2 \mathrm{HO}^{\bullet}+2 \mathrm{PH} & \rightarrow 2 \mathrm{P}^{\bullet}+2 \mathrm{H}_{2} \mathrm{O} & \left(\mathrm{k}_{10}\right) \\ & & \rightarrow 4 \mathrm{P}^{\bullet}+2 \mathrm{H}_{2} \mathrm{O}\end{array}$


(10) Initiation $\mathrm{PH}+\mathrm{O}_{2} \rightarrow 4 \mathrm{P}^{\circ}$

$\left(\mathrm{k}_{10}\right)$

(1u) Initiation $\mathrm{POOH} \rightarrow 2 \mathrm{P}^{\bullet}+\gamma_{1} \mathrm{POH}=\mathrm{O}+\gamma_{1} \mathrm{~S}$

$\left(\mathrm{k}_{1 \mathrm{u}}\right)$

(2) Propagation $\mathrm{P}^{\bullet}+\mathrm{O}_{2} \rightarrow \mathrm{PO}_{2}^{*}$

(3) Propagation $\mathrm{PO}_{2}+\mathrm{PH} \rightarrow \mathrm{POOH}+\mathrm{P}^{*}$

(4) Termination $\mathrm{P}^{\bullet}+\mathrm{P}^{\bullet} \rightarrow \gamma_{4} \mathrm{PP}+\left(1-\gamma_{4}\right) \mathrm{PH}+\left(1-\gamma_{4}\right) \mathrm{F}+\gamma_{4} \mathrm{X}\left(\mathrm{k}_{4}\right)$

(5) Termination $\mathrm{P}^{\bullet}+\mathrm{PO}_{2}^{-} \rightarrow \mathrm{POOH}+\mathrm{F}$

(60) Activated complex formation $\mathrm{PO}_{2}^{\dot{P}}+\mathrm{PO}_{2}^{\dot{2}} \rightarrow\left[\mathrm{PO}^{*} \mathrm{OP}\right]_{\text {cage }}+\mathrm{O}_{2}$

(62) Termination $\left[\mathrm{PO}^{*} \mathrm{OP}\right]_{\text {cage }} \rightarrow \mathrm{O}(\mathrm{P}=\mathrm{O})_{2}+\mathrm{POH}$

(63) Non terminating combination

$\left[\mathrm{PO}{ }^{\circ} \mathrm{OP}\right]_{\text {cage }} \rightarrow 2 \mathrm{P}^{\bullet}+2 \gamma_{1} \mathrm{POH}=\mathrm{O}+2 \gamma_{1} \mathrm{~S}$

where $\mathrm{PH}$ designates a methylene $\mathrm{C}-\mathrm{H}$ bond, $\mathrm{POOH}$ an hydroperoxide, $\mathrm{P}^{\cdot}$ an alkyl radical, $\mathrm{PO}_{2}$ a peroxy radical, $\left[\mathrm{PO}^{\circ} \mathrm{OP}\right]_{\text {cage }}$ an alkoxy radical pairs in a cage, $\mathrm{POH}=\mathrm{O}$ a carboxylic acid, $\mathrm{O}(\mathrm{P}=\mathrm{O})_{2}$ an anhydride, $\mathrm{POH}$ an alcohol, $\mathrm{PP}$ a carbon-carbon bond, $\mathrm{F}$ a vinyl double bond, $\mathrm{S}$ a chain scission and $\mathrm{X}$ a chain branching. The coefficients $\gamma_{1}$ and $\gamma_{4}$ are the respective yields of chain scissions and chain branching in the concerned reactions.

In addition, it has been seen, in Introduction, that several nonradical processes are likely to superimpose to oxidation. Among these potential mechanisms, two are the subject of a relative consensus in literature and, for this reason, they have particularly caught our attention. On one hand, there is the thermal decomposition of the ester groups of main structural irregularities, that is to say diethylene glycol units $[8,23-26]$ :

(0i) Decomposition Irreg $\rightarrow \mathrm{POH}=\mathrm{O}+\mathrm{FV}+\mathrm{S}$

$\left(\mathrm{k}_{0 \mathrm{i}}\right)$

where $\mathrm{F}_{\mathrm{V}}$ designates a vinylidene double bond and $+\mathrm{S}$ a chain scission.

On the other hand, there is the condensation of carboxylic acid chain ends pairs $[5,6,10,22,24,26]$ :

(7) Condensation $\mathrm{POH}=\mathrm{O}+\mathrm{POH}=\mathrm{O} \rightarrow \mathrm{O}(\mathrm{P}=\mathrm{O})_{2}+\mathrm{H}_{2} \mathrm{O}-\mathrm{S}\left(\mathrm{k}_{7}\right)$

where $-\mathrm{S}$ designates a chain extension.

One expects that this reaction plays effectively a role since it is favoured at high temperature, particularly in melt state, and carboxylic acids are the main initiation by-products (see reactions (1u) and (63)) in the previous mechanistic scheme. To check this assumption, molten PET has been analyzed by FTIR spectrometry in Attenuated Total Reflectance mode after $3000 \mathrm{~min}$ at $280{ }^{\circ} \mathrm{C}$ under two different oxygen partial pressures. FTIR spectra show very little differences, often of the order of the experimental scattering, but one can observe clearly, in the $1760-1820 \mathrm{~cm}^{-1}$ region, the formation of several overlapped bands which can be reasonably attributed to anhydride groups (see Fig. 5).

It is important to notice, at this stage, that each condensation event leads to a chain extension and not to a chain branching. For this reason, it can be considered as the reciprocal reaction of a chain scission.

Finally, in this study, we have chosen the mechanistic scheme composed of the 11 previous elementary reactions $\{0 \mathrm{i}, 1 \mathrm{u}, 1 \mathrm{o}, 2,3,4$, $5,60,62,63$ and 7$\}$ to tentatively describe the thermal ageing kinetics of molten PET. In the simplest case of a homogeneous oxidation (i.e. in the absence of oxidation gradients), the oxygen

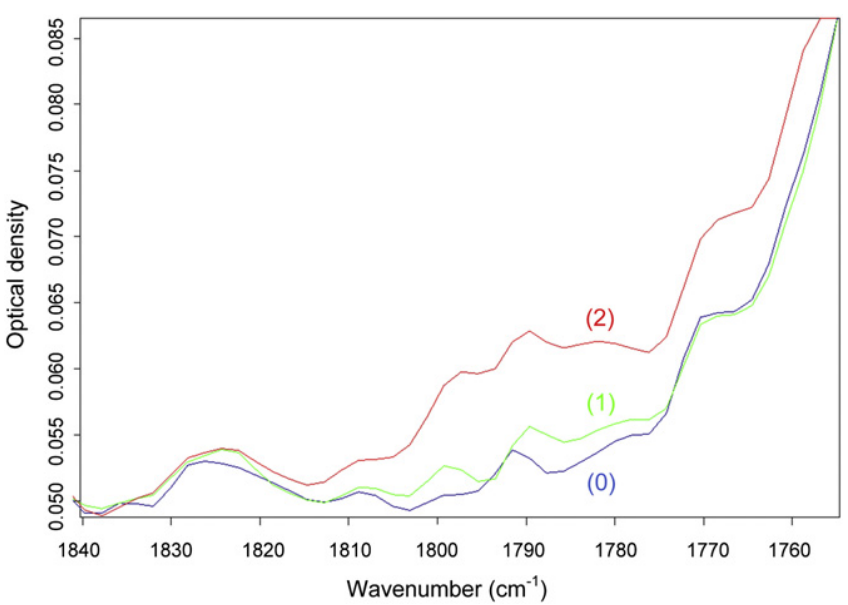

Fig. 5. Magnification of the $1750-1800 \mathrm{~cm}^{-1}$ region of FTIR spectra before (0) and after $3000 \mathrm{~min}$ at $280{ }^{\circ} \mathrm{C}$ under $1 \%$ (1) and $21 \%$ of atmospheric pressure (2).

concentration into the polymer remains constant at any place in the sample thickness. As a result, Equ. (4) can be rewritten as follows:

$\left[\mathrm{O}_{2}\right]=4.6 \times 10^{-8} \times \mathrm{P}_{\mathrm{O}_{2}}$

Thus, the mechanistic scheme leads to a system of 7 differential equations:

$\frac{\mathrm{d}[\mathrm{Irreg}]}{\mathrm{dt}}=-\mathrm{k}_{0 \mathrm{i}}[$ Irreg $]$

$\frac{\mathrm{d}[\mathrm{POOH}]}{\mathrm{dt}}=-\mathrm{k}_{1 \mathrm{u}}[\mathrm{POOH}]+\mathrm{k}_{3}[\mathrm{PH}]\left[\mathrm{PO}_{2}^{\cdot}\right]+\mathrm{k}_{5}\left[\mathrm{P}^{*}\right]\left[\mathrm{PO}_{2}^{\cdot}\right]$

$$
\begin{aligned}
\frac{\mathrm{d}\left[\mathrm{P}^{*}\right]}{\mathrm{dt}}= & 4 \mathrm{k}_{1 \mathrm{o}}[\mathrm{PH}]\left[\mathrm{O}_{2}\right]+2 \mathrm{k}_{1 \mathrm{u}}[\mathrm{POOH}]-\mathrm{k}_{2}\left[\mathrm{O}_{2}\right]\left[\mathrm{P}^{*}\right]+\mathrm{k}_{3}[\mathrm{PH}]\left[\mathrm{PO}_{2}^{\cdot}\right] \\
& -2 \mathrm{k}_{4}\left[\mathrm{P}^{\bullet}\right]^{2}-\mathrm{k}_{5}\left[\mathrm{P}^{*}\right]\left[\mathrm{PO}_{2}^{\cdot}\right]+2 \mathrm{k}_{63}\left[\mathrm{PO}{ }^{\circ} \mathrm{OP}\right]_{\text {cage }}
\end{aligned}
$$

$\frac{\mathrm{d}\left[\mathrm{PO}_{2}^{\cdot}\right]}{\mathrm{dt}}=\mathrm{k}_{2}\left[\mathrm{O}_{2}\right]\left[\mathrm{P}^{\cdot}\right]-\mathrm{k}_{3}[\mathrm{PH}]\left[\mathrm{PO}_{2}^{\cdot}\right]-\mathrm{k}_{5}\left[\mathrm{P}^{\bullet}\right]\left[\mathrm{PO}_{2}^{\cdot}\right]-2 \mathrm{k}_{60}\left[\mathrm{PO}_{2}^{\cdot}\right]^{2}$

$\frac{\mathrm{d}\left[\mathrm{PO}^{\circ} \mathrm{OP}\right]_{\text {cage }}}{\mathrm{dt}}=2 \mathrm{k}_{60}\left[\mathrm{PO}_{2}^{\cdot}\right]^{2}-\left(\mathrm{k}_{62}+\mathrm{k}_{63}\right)\left[\mathrm{PO}^{\cdot} \cdot \mathrm{OP}\right]_{\text {cage }}$

$$
\begin{aligned}
\frac{\mathrm{d}[\mathrm{PH}]}{\mathrm{dt}}= & -2 \mathrm{k}_{0 \mathrm{i}}[\mathrm{Irreg}]-4 \mathrm{k}_{1 \mathrm{o}}[\mathrm{PH}]\left[\mathrm{O}_{2}\right]-\left(2-\gamma_{1}\right) \mathrm{k}_{1 \mathrm{u}}[\mathrm{POOH}] \\
& -\mathrm{k}_{3}[\mathrm{PH}]\left[\mathrm{PO}_{2}^{\cdot}\right]-\mathrm{k}_{5}\left[\mathrm{P}^{*}\right]\left[\mathrm{PO}_{2}\right] \\
& -2\left(1-\gamma_{1}\right) \mathrm{k}_{63}\left[\mathrm{PO}^{\circ} \mathrm{OP}\right]_{\text {cage }}
\end{aligned}
$$

$$
\begin{aligned}
\frac{\mathrm{d}[\mathrm{POH}=\mathrm{O}]}{\mathrm{dt}}= & \mathrm{k}_{0 \mathrm{i}}[\mathrm{Irreg}]+\gamma_{1} \mathrm{k}_{1 \mathrm{u}}[\mathrm{POOH}] \\
& +2 \gamma_{1} \mathrm{k}_{63}\left[\mathrm{PO}{ }^{\circ} \mathrm{OP}\right]_{\mathrm{cage}}-2 \mathrm{k}_{7}[\mathrm{POH}=\mathrm{O}]^{2}
\end{aligned}
$$

which admits for initial conditions (at $\mathrm{t}=0$ ):

$$
\begin{aligned}
& -[\text { Irreg }]=[\text { Irreg }]_{0} ; \\
& -[\mathrm{POOH}]=[\mathrm{POOH}]_{0} ; \\
& -\left[\mathrm{P}^{*}\right]=\left[\mathrm{PO}_{2}^{\circ}\right]=\left[\mathrm{PO}^{\circ} \mathrm{OP}\right]_{\text {cage }}=0 ;
\end{aligned}
$$


- $[\mathrm{PH}]=[\mathrm{PH}]_{0} \approx 14 \mathrm{~mol} \mathrm{l}^{-1}$;

- and $[\mathrm{POH}=\mathrm{O}]=[\mathrm{POH}=\mathrm{O}]_{0}=\mathrm{M}_{\mathrm{nO}}^{-1}$.

(considering that all the PET chains are initially terminated by one carboxylic acid and one hydroxyl ethyl ester chain ends).

We have solved numerically the system of differential Equs. (9)(15) using the ODE23s solver of Matlab ${ }^{\circledR}$ commercial software. This is a solver based on the Rosenbrock's semi-implicit algorithm, specially adapted for solving "stiff" problems of chemical kinetics.

This system gives access to the changes in the concentration of

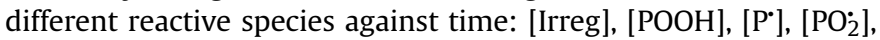
$\left[\mathrm{PO}{ }^{\circ} \mathrm{OP}\right]_{\text {cage, }}[\mathrm{PH}]$ and $[\mathrm{POH}=\mathrm{O}]=\mathrm{f}(\mathrm{t})$. From these values, it is possible to calculate the rates of the different types of macromolecular changes:

- Chain scissions:

$\frac{\mathrm{dS}_{+}}{\mathrm{dt}}=\mathrm{k}_{0 \mathrm{i}}[\mathrm{Irreg}]+\gamma_{1} \mathrm{k}_{1 \mathrm{u}}[\mathrm{POOH}]+2 \gamma_{1} \mathrm{k}_{63}\left[\mathrm{PO}{ }^{\circ} \mathrm{OP}\right]_{\text {cage }}$

- Chain extensions:

$\frac{\mathrm{dS}_{-}}{\mathrm{dt}}=\mathrm{k}_{7}[\mathrm{POH}=\mathrm{O}]^{2}$

Chain branching:

$\frac{\mathrm{dX}}{\mathrm{dt}}=\gamma_{4} \mathrm{k}_{4}\left[\mathrm{P}^{\bullet}\right]^{2}$

And, finally, chain couplings (i.e. chain scissions and branching):

$\frac{\mathrm{dS}}{\mathrm{dt}}=\frac{\mathrm{dS}_{+}}{\mathrm{dt}}-\frac{\mathrm{dS}_{-}}{\mathrm{dt}}$

Then, the Saito's equations [51] have been used to determine the number and weight average molar masses ( $M_{n}$ and $M_{W}$ respectively):

$\mathrm{S}-\mathrm{X}=\frac{1}{\mathrm{M}_{\mathrm{n}}}-\frac{1}{\mathrm{M}_{\mathrm{n} 0}}$

$\frac{S}{2}-2 X=\frac{1}{M_{W}}-\frac{1}{M_{W 0}}$

Finally, the changes in Newtonian viscosity have been calculated using the standard scale law [52,53]:

$\eta \approx \mathrm{KM}_{\mathrm{W}}^{3,4}$

with $\mathrm{K}=3.4 \times 10^{-4} \mathrm{~Pa} \mathrm{~s}\left(\mathrm{~mol}^{\mathrm{kg}-1}\right)^{3,4}$ at $280^{\circ} \mathrm{C}$ [34].

Thus, in this study, the kinetic model composed of Equs. (8)(22) was used to tentatively determine which macromolecular changes are responsible for the changes in the PET rheological behaviour during its mechanical recycling by extrusion.

\section{Materials and techniques}

\subsection{Materials}

This study has focused on 2 batches of regenerated PET supplied by SOREPLA Company (Neufchâteau, south of France). In both cases, the flakes present a low quantity of contaminants (PE $<30 \mathrm{ppm}$, PVC $<65$ ppm, metals $<5$ ppm, PAN $<10$ ppm and paper $<5$ ppm) which intend them to food packaging applications. They differ
Table 2

Main characteristics of both batches of regenerated PET under study.

\begin{tabular}{lll}
\hline References & Assadi [35] & Nait-Ali [36] \\
\hline Batch of PET & PET 1 & PET 2 \\
$\mathrm{M}_{\mathrm{W}}\left(\mathrm{kg} \mathrm{mol}^{-1}\right)$ & 55 & 63.2 \\
$\mathrm{~T}_{\mathrm{F}}\left({ }^{\circ} \mathrm{C}\right)$ & 250 & $240-250$ \\
$\mathrm{X}_{\mathrm{C}}(\%)$ & 33 & 33 \\
$\rho$ & - & 1.41 \\
\hline
\end{tabular}

mainly by their molar mass $\mathrm{M}_{\mathrm{W}}$. Their main characteristics are presented in Table 2.

\subsection{Rheological measurements}

PET flakes have been carefully dried during $15 \mathrm{~h}$ at $120^{\circ} \mathrm{C}$ under vacuum to reduce the moisture content to values below $10 \mathrm{ppm}$ and thus, to limit the risks of hydrolysis during processing at high temperature.

Then, the rheological properties of both regenerated PET have been measured in molten state at $280{ }^{\circ} \mathrm{C}$ under nitrogen with a Rheometrics Ares rheometer, using a coaxial parallel plate geometry (diameter $=50 \mathrm{~mm}$, gap $=1 \mathrm{~mm}$ ). Sweep angular frequency experiments $\left(\omega=10^{-2}-10^{2} \mathrm{rad} \mathrm{s}^{-1}\right)$ have been performed with a strain amplitude of $20 \%$. These experiments show that the rheological behaviour of both PET is Newtonian in the low frequency range, typically for $\omega \leq 10 \mathrm{rad} \mathrm{s}^{-1}$ (see Fig. 6).

These operating conditions $\left(\mathrm{T}=280{ }^{\circ} \mathrm{C}, \gamma_{\max }=20 \%\right.$ and $\omega=10 \mathrm{rad} \mathrm{s}^{-1}$ ) have been used to follow the changes in Newtonian viscosity of both PET in various oxygen atmospheres representing the real extrusion conditions, that is to say:

- A constant oxygen partial pressure: $0 ; 0,6 ; 1 ; 9$ and $21 \%$ of atmospheric pressure to reproduce the local macromolecular changes (relative predominance of chain scissions and couplings) at a position $\mathrm{z}$ in the extruder reactor;

- A variable oxygen partial pressure: alternations between $0 \%$ and $21 \%$ of atmospheric pressure to reproduce the historical background of macromolecular changes (sequences of chain scissions and chain couplings) during a complete extrusion cycle.

\section{Results and discussion}

\subsection{Iso-atmospheric experiments}

No significant difference was observed between the thermal ageing kinetics of both batches of regenerated PET supplied by

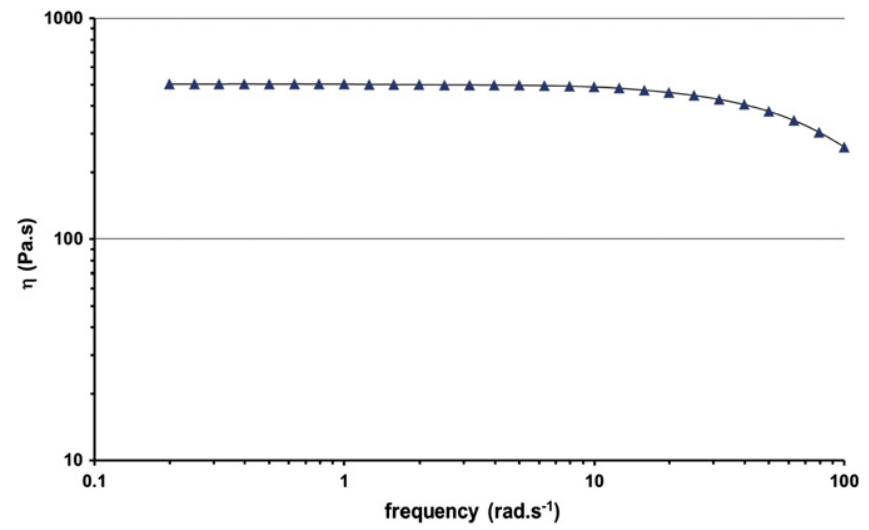

Fig. 6. Rheological behaviour of as received PET 2 - Real part of dynamic viscosity versus frequency at $280^{\circ} \mathrm{C}$. 
SOREPLA Company. Indeed, the gap between the respective changes in rheological behaviour is of the order of the experimental scattering. That is the reason why, in the next sections, the kinetic curves of Newtonian viscosity $\eta(t)$ will be normalized by their initial value $\eta(t=0)$, in order to eliminate the small initial differences between PET 1 and PET 2, and there will be no longer distinction between these polymers.

Examples of kinetic curves of Newtonian viscosity in various oxygen atmospheres are presented in Fig. 7. It can be clearly seen that the PET rheological behaviour is oxygen partial pressure dependent:

- As expected, in the absence of oxygen ( $0 \%$ of atmospheric pressure), PET is relatively stable at $280{ }^{\circ} \mathrm{C}$. Indeed, after a very slight decrease, which can be reasonably attributed to the thermal decomposition of main structural irregularities (i.e. diethylene glycol units), $\eta$ reaches an asymptotic value;

- At low oxygen partial pressures (typically for $\mathrm{P}_{\mathrm{O}_{2}}<9 \%$ of atmospheric pressure), $\eta$ increases slowly until the complete polymer gelation. Thus, chain couplings prevail on chain scissions. According to Equ. (21), we are in the case where: $S<4 X$;

- At the critical oxygen pressure of $P_{C} \approx 9 \%$ of atmospheric pressure, $\eta$ takes an almost constant value. Then, chain couplings equilibrate chain scissions and we are in the case where: $S=4 X$;

- At higher oxygen partial pressures (typically $\mathrm{P}_{\mathrm{O}_{2}}>\mathrm{P}_{\mathrm{C}}$ ), $\eta$ decreases sharply with time. Chain scissions predominate largely over chain couplings and we are in the case where: $S>4 \mathrm{X}$.

The introduction of the $P_{C}$ value in Equ. (4) allows the calculation of the critical oxygen concentration delimiting the "welloxygenated" zones from the "poorly oxygenated" zone in the extruder rector. The numerical application leads to:

$\left[\mathrm{O}_{2}\right]\left(\mathrm{z}_{1}\right)=\left[\mathrm{O}_{2}\right]\left(\mathrm{z}_{2}\right)=\left[\mathrm{O}_{2}\right]_{\mathrm{C}}=4.2 \times 10^{-4} \mathrm{~mol} \mathrm{l}^{-1}$

\subsection{Sequential experiments}

An example of kinetic curves of Newtonian viscosity $\eta$ of PET 1 during two nitrogen/air alternations under atmospheric pressure is presented in Fig. 8. One can distinguish three different stages of $\eta$ changes. Chronologically:

- The first stage corresponds to a "stabilization" phase of $\eta$ values under nitrogen. As seen in the previous section, after a very slight

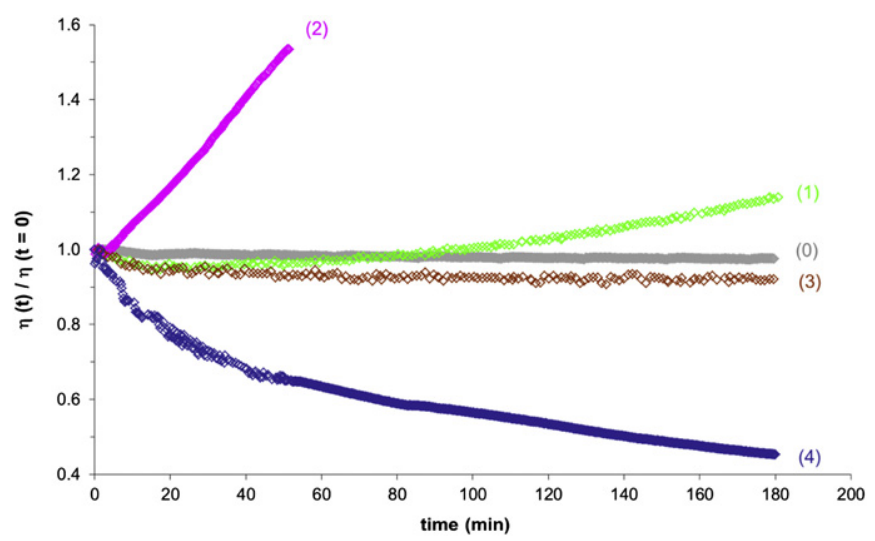

Fig. 7. Changes in Newtonian viscosity at $280{ }^{\circ} \mathrm{C}$ under various oxygen partial pressures: $0 \%(0) ; 0.6 \%(1) ; 1 \%(2) ; 9 \%(3)$ and $21 \%$ of atmospheric pressure (4).

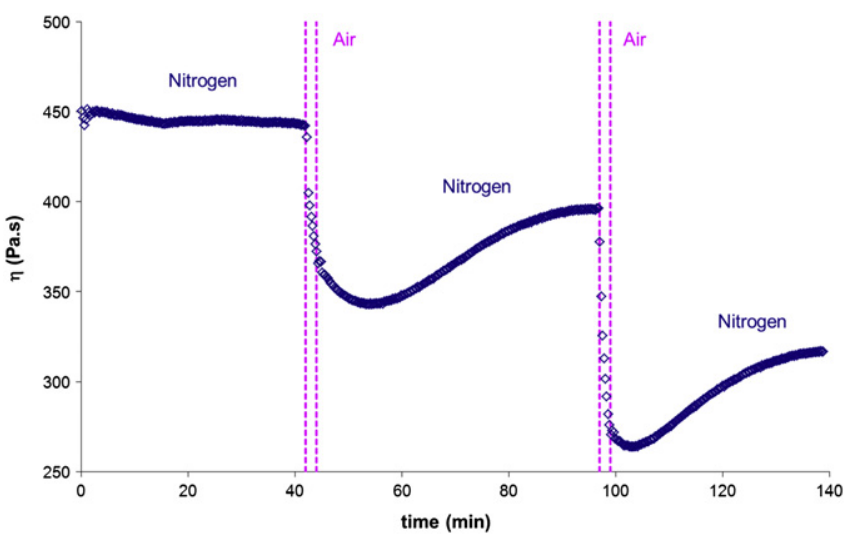

Fig. 8. Changes in Newtonian viscosity at $280^{\circ} \mathrm{C}$ during two nitrogen/air alternations under atmospheric pressure. Duration of successive exposures under nitrogen: 42, 53 then $40 \mathrm{~min}$. Duration of exposures under air: $2 \mathrm{~min}$ in both cases.

decrease, which can be reasonably attributed to the thermal decomposition of main PET structural irregularities (i.e. diethylene glycol units), $\eta$ reaches an asymptotic value;

- The second stage corresponds to a dramatic drop of $\eta$ in ambient air. In this narrow interval, nitrogen has been replaced by atmospheric air during approximately 2 min in the rheometer cavity. Thus, chain scissions predominate largely over chain couplings. One can notice the absence of induction time, since the decreasing rate of $\eta$ is maximum from the introduction of air into the cavity. This is an important argument in favour of the existence of an extrinsic initiation mechanism of thermal oxidation. The direct reaction of molecular oxygen with the polymer (10) should allow to describe, without the use of an additional assumption or adjustable parameters, this important characteristic of the thermal oxidation kinetics of molten PET at $280{ }^{\circ} \mathrm{C}$;

- The third stage corresponds to a non-monotonous change in $\eta$ when the oxygen partial pressure decreases from $21 \%$ to $0 \%$ of atmospheric pressure. In this interval, ambient air has been replaced by nitrogen in the rheometer cavity, until the complete stabilization of $\eta$ values. One observes, at first, a slowdown of the $\eta$ decrease, previously initiated under atmospheric air, leading to a minimum value of $\eta$, presumably reached when the oxygen partial pressure equals $9 \%$ of atmospheric pressure. It is, indeed, at this critical value that chain couplings equilibrate chain scissions (see Fig. 7). Once the oxygen partial pressure becomes lower than this critical value, chain couplings predominate over chain scissions and one observes a re-increase in $\eta$. This final increase stops when oxygen is totally consumed in the rheometer cavity.

\subsection{Kinetic modelling}

We have used the kinetic model, composed of Equs. (8)-(22), to tentatively simulate the kinetic curves of $\eta$ presented in Figs. 7 and 8. The values of initial concentrations, rate constants and yields used for all the simulations, at $280{ }^{\circ} \mathrm{C}$, are reported in Tables 3 and 4 .

These values call for the following comments:

i) The initial concentration of structural irregularities $\approx$ $2.4 \times 10^{-3} \mathrm{~mol} \mathrm{l}^{-1}$ is quite reasonable. It represents about $1.7 \mathrm{~mol} \%$ of monomer units, which is in perfect agreement with literature data [22]; 
Table 3

Initial concentrations (in $\mathrm{mol} \mathrm{l}^{-1}$ ) of the different reactive species.

\begin{tabular}{ll}
\hline Concentration & Value \\
\hline$[\text { Irreg }]_{0}$ & $2.4 \times 10^{-3}$ \\
{$[\mathrm{POOH}]_{0}$} & $10^{-4}$ \\
{$[\mathrm{PH}]_{0}$} & 14 \\
{$[\mathrm{POH}=\mathrm{O}]_{0}$} & $2.1-2.4 \times 10^{-2}$ \\
\hline
\end{tabular}

ii) The rate constants $k_{1 u}-k_{63}$, except $k_{4}$, have been determined in a previous study for PE [49]. Values of $\mathrm{k}_{4}$ greater than $10^{12} \mathrm{l} \mathrm{mol}^{-1} \mathrm{~s}^{-1}$ are, a priori, difficult to explain in the case of scarce species such as alkyl radicals. However, it is expected that, at high temperature, in molten state, the reaction of hydrogen transfer by valence migration plays a key role:

$\mathrm{P}^{\bullet}+\mathrm{PH} \rightarrow \mathrm{PH}+\mathrm{P}^{\cdot}$

iii) The rate constants $\mathrm{k}_{10}, \mathrm{k}_{0 \mathrm{i}}$ and $\mathrm{k}_{7}$, but also the yields $\gamma_{1}$ and $\gamma_{4}$, have been determined in this study. The value of the rate constant $\mathrm{k}_{1 \mathrm{o}} \approx 9 \times 10^{-4} \mathrm{l} \mathrm{mol}^{-1} \mathrm{~s}^{-1}$ is high enough to destroy the "closed-loop" character of oxidation mechanism. Indeed, we are in the situation where the initial rates of radical production by reactions (10) and ( $1 \mathrm{u}$ ) are of the same order of magnitude. As an example, in atmospheric air, these rates can be written:

$\mathrm{v}_{1 \mathrm{o}}=4 \mathrm{k}_{1 \mathrm{o}}[\mathrm{PH}]_{0}\left[\mathrm{O}_{2}\right] \approx 4.9 \times 10^{-5} \mathrm{~mol} \mathrm{l}^{-1} \mathrm{~s}^{-1}$

and $\mathrm{v}_{1 \mathrm{u}}=\mathrm{k}_{1 \mathrm{u}}[\mathrm{POOH}]_{0} \approx 5.0 \times 10^{-5} \mathrm{~mol} \mathrm{l}^{-1} \mathrm{~s}^{-1}$

That is to say that: $\mathrm{v}_{10} \approx \mathrm{v}_{1 \mathrm{u}}$

On the contrary, the initial concentration of carboxylic acids $\approx 2.2 \times 10^{-2} \mathrm{~mol} \mathrm{l}^{-1}$ and the value of rate constant $\mathrm{k}_{7} \approx 1.7 \times 10^{-6} 1 \mathrm{~mol}^{-1} \mathrm{~s}^{-1}$ are too low to generate, in the timescale of a few extrusion cycles, a sufficient number of chain extensions and thus, to impact the rheological behaviour of the molten polymer. But, at longer term, when a large amount of carboxylic acids will be accumulated into the reactive medium, it is conceivable that this reaction will play, in turn, a major role.

As a consequence, at low oxygen partial pressure (typically for $\mathrm{P}_{\mathrm{O}_{2}}<9 \%$ of atmospheric pressure), chain branching is the main source of problems during the PET mechanical recycling by

Table 4

Parameters used for kinetic modelling at $280^{\circ} \mathrm{C}$.

\begin{tabular}{lcl}
\hline Parameter & Value & Unit \\
\hline $\mathrm{k}_{0 \mathrm{i}}$ & $7.1 \times 10^{-4}$ & $\mathrm{~s}^{-1}$ \\
$\mathrm{k}_{1 \mathrm{o}}$ & $9 \times 10^{-4}$ & $1 \mathrm{~mol}^{-1} \mathrm{~s}^{-1}$ \\
$\mathrm{k}_{1 \mathrm{u}}$ & $5 \times 10^{-1}$ & $\mathrm{~s}^{-1}$ \\
$\mathrm{k}_{2}$ & $10^{8}$ & $1 \mathrm{~mol}^{-1} \mathrm{~s}^{-1}$ \\
$\mathrm{k}_{3}$ & $1.9 \times 10^{3}$ & $1 \mathrm{~mol}^{-1} \mathrm{~s}^{-1}$ \\
$\mathrm{k}_{4}$ & $6 \times 10^{13}$ & $1 \mathrm{~mol}^{-1} \mathrm{~s}^{-1}$ \\
$\mathrm{k}_{5}$ & $4 \times 10^{11}$ & $1 \mathrm{~mol}^{-1} \mathrm{~s}^{-1}$ \\
$\mathrm{k}_{60}$ & $10^{10}$ & $1 \mathrm{~mol}^{-1} \mathrm{~s}^{-1}$ \\
$\mathrm{k}_{62}$ & $4 \times 10^{5}$ & $\mathrm{~s}^{-1}$ \\
$\mathrm{k}_{63}$ & $10^{8}$ & $\mathrm{~s}^{-1}$ \\
$\mathrm{k}_{7}$ & $1.7 \times 10^{-6}$ & $1 \mathrm{~mol}^{-1} \mathrm{~s}^{-1}$ \\
$\gamma_{1}$ & 83.9 & $\%$ \\
$\gamma_{4}$ & 17.4 & $\%$ \\
\hline
\end{tabular}

extrusion. The yield $\gamma_{4}$ for coupling of alkyl radicals is about $17 \%$ at $280^{\circ} \mathrm{C}$. This reaction is in competition with disproportionation:<smiles>CCC(CC)[C@H](CC)OC</smiles>

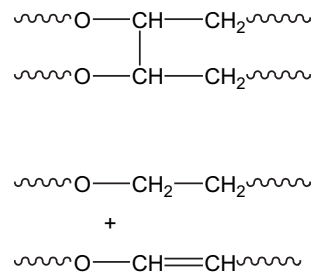

On the contrary, at higher oxygen partial pressure $\left(\mathrm{P}_{\mathrm{O}_{2}}>9 \%\right.$ of atmospheric pressure), chain scissions are the main source of problems during the PET mechanical recycling by extrusion. The yield $\gamma_{1}$ for $\beta$ scissions of alkoxy radicals is about $84 \%$ at $280^{\circ} \mathrm{C}$. This reaction is in competition with hydrogen abstraction:
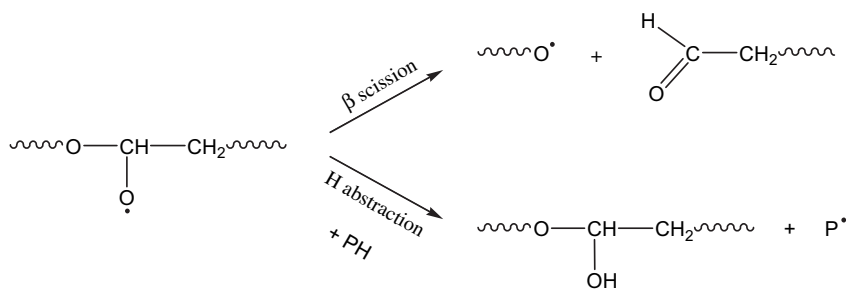

Examples of simulation of the kinetic curves of $\eta$ are reported in Figs. 9 and 10. It can be seen that the kinetic model describes satisfyingly the experimental results, as well under constant oxygen partial pressures as under variable oxygen partial pressures. It can be thus considered that the validity of the kinetic model has been successfully checked.

As suspected in the previous section, at longer term, chain extensions affect, in turn, the rheological behaviour of PET (see Fig. 11). Indeed, after about $275 \mathrm{~min}$ of exposure at $280{ }^{\circ} \mathrm{C}$ in ambient air, one observes a re-increase in $\eta$, presumably until the complete polymer gelation (by crosslinking). At this stage, chain extensions would represent less than $2 \mathrm{~mol} \%$ of the total

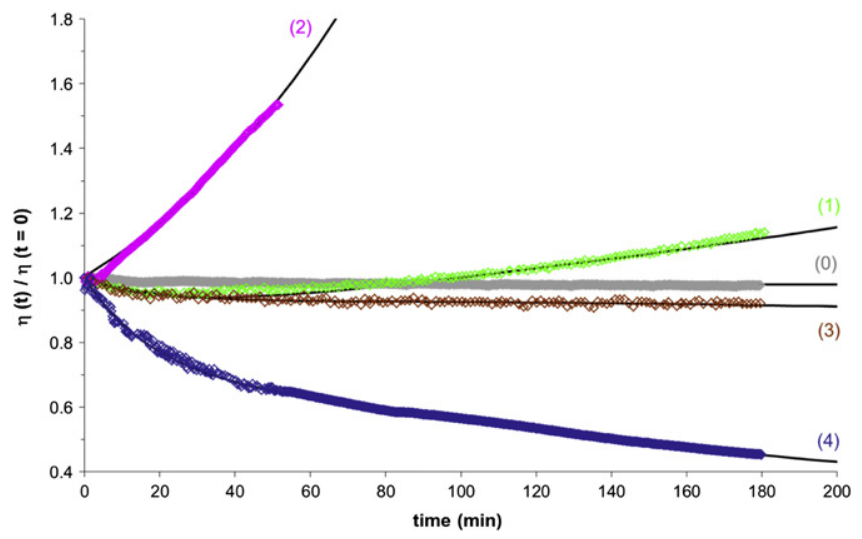

Fig. 9. Simulations of the kinetic curves of Newtonian viscosity at $280{ }^{\circ} \mathrm{C}$ under various oxygen partial pressures: $0 \%(0) ; 0.6 \%(1) ; 1 \%(2) ; 9 \%(3)$ and $21 \%$ of atmospheric pressure (4). Dots: experimental data. Curves: kinetic model. 


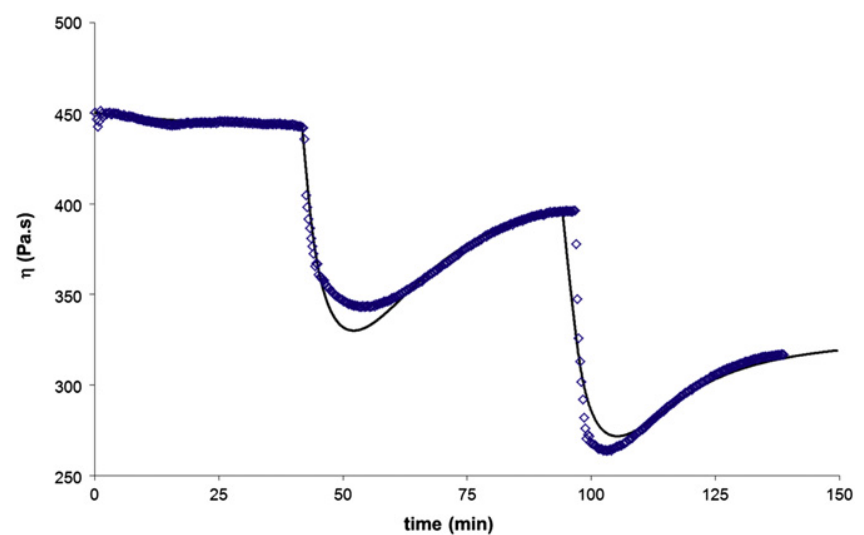

Fig. 10. Simulation of the kinetic curve of Newtonian viscosity at $280{ }^{\circ} \mathrm{C}$ during two nitrogen/air alternations under atmospheric pressure. Dots: experimental data. Curves: kinetic model.

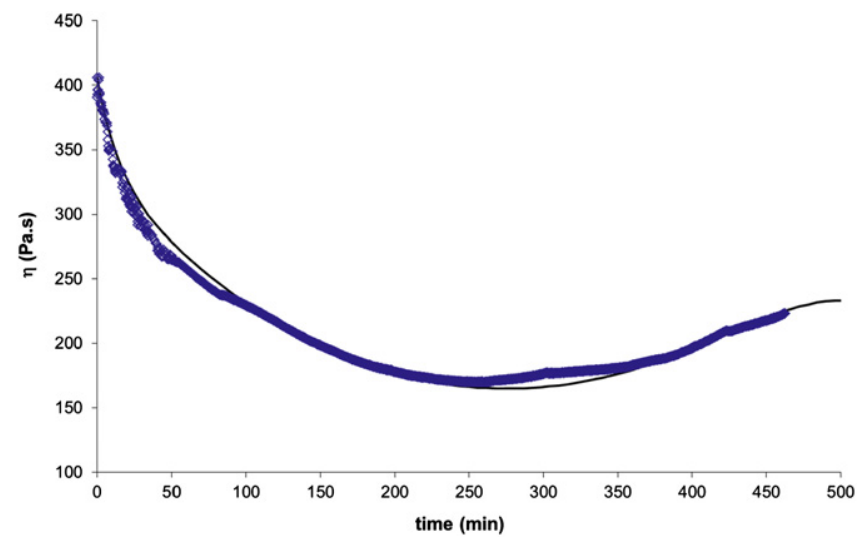

Fig. 11. Simulation of the kinetic curve of Newtonian viscosity at $280{ }^{\circ} \mathrm{C}$ under atmospheric air. Dots: experimental data. Curves: kinetic model.

concentration of chain couplings. But, this small contribution seems to be sufficient to fully offset the effect of chains scissions.

It can be seen that, here also, the kinetic model describes perfectly this evolution, which confirms its high predictive value.

\section{Conclusions}

During its mechanical recycling by extrusion, PET undergoes reversible modifications of its macromolecular structure induced by hydrolysis, esterification and transesterification reactions. But, it also undergoes irreversible macromolecular changes generated by a large variety of (radical but also ionic) chemical processes.

Since an extruder is a relatively complex reactor (existence of oxygen concentration, temperature and shear gradients), we have chosen the rheometer cavity to study these macromolecular changes and their consequences on the rheological properties, in carefully controlled exposure conditions.

These experiments allow us to establish that polymer thermal oxidation is, by far, the main source of problems. Chain scissions predominate in "well-oxygenated" zones (at the feeder and die), whereas chain couplings predominate in "poorly oxygenated" zones (in the middle) of the extruder reactor. As a result, the relative predominance of both types of macromolecular changes is closely related to the extruder geometry and size (especially, the feeder and die sections and the screw length), that explains the large disparity of rheological behaviours reported in the literature.
In the timescale of a few extrusion cycles, chain couplings consist essentially in chain branchings. But, at longer term, chain extensions can, in turn, play a major role.

In parallel, we have derived, from the "closed-loop" oxidation mechanistic scheme established for a poly(methylenic) substrate in a previous study [50], a kinetic model for the thermal ageing of molten PET at high temperature in order to check these assumptions. This model describes satisfyingly all the rheological results obtained at $280{ }^{\circ} \mathrm{C}$ under constant oxygen partial pressures, but also under variable oxygen partial pressures (between $0 \%$ and $21 \%$ of atmospheric pressure).

\section{References}

[1] Leaversuch RD. Chemical recycling brings real versatility to solid-waste management. Mod Plast 1991;68:40-3.

[2] Launay A, Thominette F, Verdu J. Hydrolysis of poly(ethylene terephthalate): a kinetic study. Polym Degrad Stab 1994;46:319-24.

[3] Zimmermann H. Degradation and stabilization of polyesters. In: Grassie N, editor. Developments in polymer degradation, vol. 5. London, New York: Applied Science Publishers; 1984. p. 79-119.

[4] Culbert B, Christel A. Continuous solid-state polycondensation of polyesters. In: Scheirs J, Long TE, editors. Modern polyesters: chemistry and technology of polyesters and copolyesters. Sussex (England): John Wiley \& Sons Ltd (Wiley series in Polymer Science); 2003. p. 143-94.

[5] Goodings EP. Thermal degradation of polyethylene terephthalate. J Soc Chem Ind (London) Monogr 1961;13:211-28.

[6] Buxbaum LH. The degradation of poly(ethylene terephthalate). Angew Chem Int Ed Engl 1968;7(3):182-90.

[7] Zimmerman H, Kim NT. Investigations on thermal and hydrolytic degradation of poly(ethylene terephthalate). Polym Eng Sci 1980;20(10):680-3.

[8] Khemani KC. A novel approach for studying the thermal degradation and for estimating the rate of acetaldehyde generation by the chain scission mechanism in ethylene glycol based polyesters and copolyesters. Polym Degrad Stab 2000;67:91-9.

[9] Yoda K, Tsuboi A, Wada M, Yamareda R. Network formation in poly(ethylene terephthalate) by thermooxidative degradation. J Appl Polym Sci 1970;14: 2357-76.

[10] McNeil IC, Bounekhel M. Thermal degradation studies of terephthalate polyesters: 1. Poly(alkylene terephthalates). Polym Degrad Stab 1991;34: 187-204.

[11] Pohl H. The thermal degradation of polyesters. J Am Chem Soc 1951;73: 5660-1.

[12] Montaudo G, Puglisi C, Samperi F. Primary thermal degradation mechanisms of PET and PBT. Polym Degrad Stab 1993;42:13-28.

[13] Villain F, Coudane J, Vert M. Thermal degradation of poly(ethylene terephthalate) and estimation of volatile degradation products. Polym Degrad Stab 1994;43:431-40.

[14] Samperi F, Puglisi C, Alicata R, Montaudo G. Thermal degradation of poly (ethylene terephthalate) at the processing temperature. Polym Degrad Stab 2004;83:3-10

[15] Edge M, Allen NS, Wiles R, McDonald WA, Mortlock SV. Identification of luminescent species contributing to the yellowing of poly(ethylene terephthalate) on degradation. Polymer 1995;36(2):227-34.

[16] Edge M, Wiles R, Allen NS, McDonald WA, Mortlock SV. Characterization of the species responsible for yellowing in melt degraded aromatic polyesters I: yellowing of poly(ethylene terephthalate). Polym Degrad Stab 1996;53: $141-51$.

[17] Kovarskaya BM, Levanstovskaya II, Blumenfeld AB, Draluk GV. Plast Massy. 1968;5: 42-46.

[18] Marshall I, Todd A. The thermal degradation of polyethylene terephthalate. Trans Faraday Soc 1953;49:67-78.

[19] Ciolacu CFL, Choudhury NR, Dutta NK, Voelcker NH. Maldi-Tof MS and DiosMS investigation of the degradation and discolouration of poly(ethylene terephthalate). Macromolecules 2006;39:7872-81.

[20] Holland BJ, Hay JN. The thermal degradation of PET and analogous polyesters measured by thermal analysis-Fourier transform infrared spectroscopy. Polymer 2002;43:1797-804.

[21] Botelho G, Queiros A, Gijsman P. Studies on thermal and thermo-oxidative degradation of poly(ethylene terephthalate) and poly(butylene terephthalate). Polym Degrad Stab 2001;74:39-48.

[22] Halek GW. The zero-order kinetics of acetaldehyde thermal generation from polyethylene terephthalate. J Polym Sci: Polym Symp 1986;74(1):83-92.

[23] MacDonald WA. New advances in poly(ethylene terephthalate) polymerization and degradation. Polym Int 2002;51:923-30.

[24] Romao W, Franco MF, Corilo YE, Eberlin MN, Spinacé MAS, De Paoli M-A. Poly (ethylene terephthalate) thermo-mechanical and thermo-oxidative degradation mechanisms. Polym Degrad Stab 2009;94(10):1849-59.

[25] Lecomte HA, Ligat JJ. Degradation mechanism of diéthylène glycol units in a terephthalate polymer. Polym Degrad Stab 2006;91:681-9. 
[26] Ciolacu CFL, Choudhury NR, Dutta NK. Colour formation in poly(ethylene terephthalate) during melt processing. Polym Degrad Stab 2006;91:875-85.

[27] Botelho G, Queiros A, Gijsman P. Thermo-oxidative studies of poly(etheresters). 1. Copolymer of poly(butane terephthalate) and poly(ethylene oxide). Polym Degrad Stab 2000;67:13-20.

[28] Yang J, Xia Z, Kong F, Ma X. The effect of metal catalyst on the discoloration of poly(ethylene terephthalate) in thermo-oxidative degradation. Polym Degrad Stab 2010;95(1):53-8.

[29] Scheirs J. Polymer recycling: science, technology and application. Sussex (England): John Wiley \& Sons Ltd (Wiley series in Polymer Science); 1998. p. 120-182.

[30] Colin X, Verdu J. Polymer degradation during processing. CR Chim Acad Sci 2006;9(11-12):1380-90.

[31] La Mantia FP, Vinci M. Recycling poly(ethylene terephthalate). Polym Degrad Stab 1994;45:121-5.

[32] Paci M, La Mantia FP. Competition between degradation and chain extension during processing of reclaimed poly(ethylene terephthalate). Polym Degrad Stab 1998;61:417-20.

[33] Frounchi M. Studies on degradation of PET mechanical recycling. Macromol Symp 1999;144:465-9.

[34] Spinacé MAS, De Paoli M-A. Characterization of poly(ethylene terephthalate) after multiple processing cycles. J Appl Polym Sci 2001;80:20-5.

[35] Assadi R, Colin X, Verdu J. Irreversible structural changes during PET recycling by extrusion. Polymer 2004;45(13):4403-12.

[36] Nait-Ali KL, Colin X, Bergeret A, Ferry L, Ienny P. Rheological modelisation of PET degradation during its recycling by extrusion. In: Proceedings 23rd annual meeting polymer processing society (cd-rom); 2007. 8 p.

[37] Badia JD, Vilaplana F, Karlsson S, Ribes-Greus A. Thermal analysis as a quality tool for assessing the influence of thermo-mechanical degradation on recycled poly(ethylene terephthalate). Polym Test 2009;28:169-75.

[38] Oromiehie A, Mamizadeh A. Recycling PET beverage bottles and improving properties. Polym Int 2004;53:728-32.

[39] Mancini SD, Zanin M. Recyclability of PET from virgin resin. Mater Res 1999;2 (1):33-8.
[40] Torres N, Robin J-J, Boutevin B. Study of thermal and mechanical properties of virgin and recycled poly(ethylene terephthalate) before and after injection moulding. Eur Polym J 2000;36(10):2075-80.

[41]. Mancini SD, Zanin M. Consecutive steps of PET recycling by injection: evaluation of the produce of the mechanical properties. J Appl Polym Sci 2000;76:266-75.

[42] Jabarin SA, Lofgren EA. Thermal stability of polyethylene terephthalate. Polym Eng Sci 1984;24(13):1056-63.

[43] Villain F, Coudane J, Vert M. Titration of aldehydes present in poly(ethylene terephthalate). J Appl Polym Sci 1994;52:55-60.

[44] Fayolle B, Richaud E, Colin X, Verdu J. Review: degradation-induced embrittlement in semi-crystalline polymers having their amorphous phase in rubbery state. J Mater Sci 2008;43:6999-7012.

[45] Sobue H, Kajiura J. Kogyo Kagaku Zasshi, J Chem Soc Japan Ind Chem Sect 1959;62:1766.

[46] Paci M, La Mantia FP. Influence of small amounts of polyvinylchloride on the recycling of poly(ethylene terephthalate). Polym Degrad Stab 1999;63:11-4

[47] Audouin L, Langlois V, Verdu J, De Bruijn JCM. Role of oxygen diffusion in polymer ageing: kinetic and mechanical aspects. J Mater Sci 1994;29: 569-83.

[48] Van Krevelen DW, Hoftyzer PJ. Properties of polymers. Their estimation and correlation with chemical structure. 2nd ed. Amsterdam: Elsevier; 1976. p. 406.

[49] Stannett V. Simples gases. In: Crank J, Park GS, editors. Diffusion in polymers. London: Academic Press; 1968. p. 46-50.

[50] Colin X, Audouin L, Verdu J, Rozental-Evesque M, Rabaud B, Martin F, et al Aging of polyethylene pipes transporting drinking water disinfected by chlorine dioxide. I-Chemical aspects. Polym Eng Sci 2009;49(7):1429-37.

[51] Saito O. Effects of high energy radiation to polymers. J Phys Soc Jpn 1958;13 (2):198-206. and 13(12), 1451-1464 (1958).

[52] Bueche F. The viscoelastic properties of plastics. J Chem Phys 1954;22 (4):603-9.

[53] Bueche F. Viscoelastic properties of polymers in concentrated solution. J Chem Phys 1956;25(3):599-601. 